\title{
An analysis of media reporting on the closure of freestanding midwifery units in England
}

Juliet Rayment ${ }^{\mathrm{a}}$, Christine McCourt , Miranda Scanlon , Lorraine Culley , Helen Spiby , Simon Bishop , Layara Avila de Lima ${ }^{\mathrm{c}}$

${ }^{a}$ City, University of London, 1 Myddelton Street, London, EC1R 1UB, UK

${ }^{\mathrm{b}}$ De Montfort University, The Gateway, Leicester, LE1 9BH, UK

' University of Nottingham, University Park, Nottingham, NG7 2RD, UK

d Universidade federal do Rio de Janeiro, 275 - Cidade Nova, Rio de Janeiro, RJ, 20071-003, Brazil

\begin{abstract}
Problem: Despite clinical guidelines and policy promoting choice of place of birth, 14 Freestanding Midwifery Units were closed between 2008 and 2015, closures justified in the media by low use and financial constraints.

Background: The Birthplace in England Programme found that freestanding midwifery units provided the most cost-effective birthplace for women at low risk of complications. Women planning birth in a freestanding unit were less likely to experience interventions and serious morbidity than than those planning obstetric unit birth, with no difference in outcomes for babies.
\end{abstract}

Methods: This paper uses an interpretative technique developed for policy analysis to explore the representation of these closures in 191 news articles, to explore the public climate in which they occurred.

Findings and discussion: The articles focussed on underuse by women and financial constraints on services. Despite the inclusion of service user voices, the power of framing was held by service managers and commissioners. The analysis exposed how neoliberalist and austerity policies have privileged representation of individual consumer choice and market-driven provision as drivers of changes in health services. This normative framing presents the reasons given for closure as hard to refute and cultural norms persist that birth is safest in an obstetric setting, despite evidence to the contrary.

Conclusion: The rise of neoliberalism and austerity in contemporary Britain has influenced the reform of maternity services, in particular the closure of midwifery units. Justifications given for closure silence other narratives, predominantly from service users, that attempt to present women's choice in terms of rights and a social model of care.

\section{Statement of significance}

\section{Problem or issue}

14 FMUs in England were closed between 2008 and 2015, justified in media reporting in terms of low use and costs.

\section{What is already known?}


Media representation of birth is negative and reproduces social norms, privileging a medical model. Audiences are familiar with the frames of individual

\section{What this paper adds}

Despite high numbers of service user voices, the power of framing is instead held by service managers and commissioners. British neoliberalist and austerity policies privilege individual consumer choice and market-driven provision and reinforce rationales for closure. They replicate social norms about place of birth and silence alternative voices.

\section{Introduction}

This article presents the findings of part of a wider mixed- methods study which mapped the numbers and types of midwifery units in England and explored factors influencing women's choice to use them; whether services develop and sustain them and why some units have closed. The mapping phase of the study ${ }^{1}$ identified that 14 freestanding midwifery units (FMUs) in England had been closed permanently in the eight years prior to the analysis. Here we explore the representation of the closure of these units in print and television media to better understand the rationale for closure decisions and the climate or 'public atmosphere' in which decisions took place.

Public discourse around birth has the potential to shape the experiences and beliefs of a wide group of individuals. Where this discourse occurs outside the maternity care community, for example in internet fora and newspaper and television media, it can be assumed to both reflect and illuminate the strong cultural norms and influences that shape the provision of maternity services. The norms around place of birth are themselves shaped by concepts of risk and safety, community and local belonging as well as familial influences and traditions. FMUs function (and open and close) within the influence of these norms.

The aim of this project was to explore what an analysis of media coverage of the closure of FMUs tells us about the impact of pervading cultural norms around place of birth in England: what reasons are given for the closures of FMUs? How are these closures presented publicly and by whom? What impact might this have on sustaining and/or challenging these norms?

The analysis also presented an opportunity to evaluate the effectiveness of an interpretative technique for policy analysis ${ }^{2}$ to analyse news media (as opposed to policy) and any advantage it might offer over a more conventional frame analysis.

\section{What is a freestanding midwifery unit?}

An FMU is a birth setting staffed by midwives and often also maternity support workers, that is situated on a different site from a local obstetric unit, providing midwife-led care to women with straightforward, healthy pregnancies. If women require medical care in labour, transfer involves a journey by ambulance or car. FMUs have a long history in England. Previously often known as 'maternity homes' or 'GP units', they fell out of favour in the 1970s and 80 s with the wholesale move of birth into hospital. ${ }^{3}$ During the 1990s their numbers increased again with a later shift in maternity policy that advocated choice of place of birth for women, including midwife-led birth places. $^{4-6}$ Many of the FMUs that have opened recently are the result of the consolidation and closure of obstetric services, commonly in smaller towns, by NHS Trusts to save money. 
The Birthplace in England study ${ }^{7,8}$ provided the best evidence to date of the safety of different planned places of birth for women with straightforward pregnancies. Births planned in FMUs had significantly lower rates of intervention and serious morbidity for women as compared with births planned in obstetric units and alongside midwife-led units (situated adjacent to or on the same site as an obstetric unit), with no difference in outcomes for babies. FMUs were found to be the most cost-effective birth place for this group of women.

Despite persuasive evidence in favour of FMUs, there has been a stagnation in their numbers: 58 FMUs in 2010 and 61 in 2016, caring for 2\% of births. ${ }^{1}$ Moreover, between 2001 and 2013, 21 FMUs were closed and 30 opened, suggesting issues with sustainability. ${ }^{10}$ This contrasts with a significant increase in the numbers of AMUs in England in recent years from 53 in 2010 to 97 in 2016, with 12\% of women giving birth in such units in 2016.

\section{Method}

We carried out a systematic search of newspaper and other media sources using the Lexis Nexis databases to identify all media reports directly relating to the 14 FMUs in England that had closed between 2008 and 2015. Multiple FMUs from the same NHS Trust or community area were considered as one service (See Fig. 1). The searches were screened for relevance and duplication. After screening, two FMU services were found to have no relevant articles, leaving a remaining eight services. The number of articles about each service ranged from 2 to 65 . A total of 191 articles were included in the analysis. These comprised local newspaper articles $(n=175)$, transcripts of local television news items ( $n=5$ ) (all from one site) and articles from national publications (both newspapers industry publications) $(n=11)$.

\subsection{Analysis}

Data were extracted onto a bespoke template in Microsoft Excel (Fig. 2), which provided a framework for analysis, working on two levels: (1) to identify and analyse the relevant content; (2) to identify and analyse the discourse present in the media reporting in each case. This method recognised that media analysis does not capture events as 'facts' but representations of them. The template was drafted in relation to the study objectives. It was revised within the research team where necessary in the light of the initial data extraction work. Team members extracted data using a separate sheet for each media report. Using a purpose built macro, the data were then collated into a single spreadsheet for each site and a thematic approach was used to synthesise the findings within and then across all services.

\subsection{Framing}

The production of news articles is framed by journalists' decisions on which issues to write about and which to highlight or underplay. ${ }^{11}$ These are influenced by editorial policies, the journalist's assumptions or standpoint, authors of any press releases, interviewees and other stakeholders, especially those that are socially elite:

Knowledges are produced within power relations also in the sense that some groups or institutions have been able to speak knowledgeably about "others", subaltern groups, who were concomitantly rendered silent $^{12: 15}$ 
This framing occurs again in the reception of the news and the way in which it is understood and interpreted by its audience. A reader's response to a news article is likewise affected by their preexisting ideas about the topic and the prevailing cultural norms that they are already familiar with. Rather than radically changing their mind, an article is more likely to be accepted if it is congruent with what a reader already thinks: 'an audience member's pre- existing cognitive schema or knowledge structures will determine the degree to which a frame will resonate'. ${ }^{13: 13}$ Our analysis was confined to the media content and discourse, rather than its reception.

\section{Media and childbirth}

The limited research around the presentation of birth in mass media has found an almost exclusively negative portrayal. A scoping review ${ }^{14}$ of studies of mass media (mostly television) portrayals of childbirth and their impact on women's experiences found an overwhelmingly negative depiction of birth as medicalised, risky, dangerous and to be feared. This media was a dominant way in which women learned about childbirth and birth was absent as a normal "everyday" life event. ${ }^{14}$ A content analysis of the portrayal of birth in print media elicited the categories of 'fear, ordeal, pain, effective staff, malicious or poor care'. ${ }^{15}$ Dahlen's analysis of the 2017 news media storm around the use of the term 'normal' birth ${ }^{16}$ examines these depictions within the 'post-truth' landscape of an increasingly fragmented and unaccountable online news media. Indeed, social media's influence on individual women's perceptions and choices may well be far stronger than print media, but print media continues to both reflect and shape the dominant discourses in circulation which makes it a valuable object of study if we wish to explore the cultural landscape in which maternity services function.

\section{Findings}

\subsection{What is the problem represented to be?}

In the Preface to her book, 'Analysing Policy: What's the problem represented to be?' ${ }^{2}$, Carol Bacchi introduces her readers to what she terms a 'post-structural approach to analysing policy' ${ }^{2: \text { vi }}$. Bacchi's premise is that the kinds of social problems that policy is designed to solve do not exist outside of the policy itself. Rather, in the process of developing policy-based solutions, policy-makers also construct the problems the policy aims to resolve:

Policy makers are the ones who do the fixing. The notion of 'fixing' carries with it an understanding that something needs to be 'fixed', that there is a problem. This presumed 'problem' can be, but does not need to be, explicitly elaborated. That is, most government policies do not officially declare that there is a problem that the policy will address and remedy. Rather this is implicit in the whole notion of policy by their nature policies make changes, implying that something needs to change. ${ }^{2:}$

Whilst policy is trying to 'fix' things, media articles present to the public a report of what those things are - both the solutions and the problems they purport to solve. Like policy documents,

media such as newspaper articles, television and other news present a version of social issues that are shaped by the players involved in constructing the story. We suggest that 'What's the problem represented to be?' (WPR) could be readily applied to analyse these same phenomena in newspaper articles as in policy documents. This approach invites the analyst to interrogate the subject matter using six questions. ${ }^{2: 2}$ In this paper we address these questions to explore the ways in which 
problems and solutions are presented and to interrogate the taken-for-granted presuppositions that help to construct them.

\subsection{Content analysis}

A preliminary analysis of the basic content of the articles revealed a number of trends. We were particularly interested in the reasons given for the closures, whose voice predominated in the articles and what that might tell us about the relative power of the different players in the media representations of these closures.

There were two predominant reasons for closure given in the articles: under-use of the units $(n=56)$ and the high cost of running them $(n=48)$ (see Fig. 3). These articles far superseded any other reasons, such as staffing concerns (the next most common at $n=17$ ). Reports frequently detailed the proposed changes to services, but very little reporting included broader information about midwifery units, any reference to safety or the use of clinical evidence.

In relation to the voices represented, a count of the articles quoting different speakers found 46 articles that quoted service users, as compared with health service commissioners $(n=24)$, local council politicians $(n=24)$ and senior hospital staff $(n=22)$ (See Fig. 4). This preponderance of service user voices might suggest that they held the narrative power when articulating their campaign demands to retain the FMUs. However, a deeper investigation of the narratives, norms and assumptions at play using WPR analysis exposed a different dynamic.

\subsection{A "What's the Problem Represented to be?" analysis}

\subsubsection{Question 1: What's the 'problem' represented to be in a specific policy (or this group of articles)?}

The articles reported on planned or proposed changes that all involved the closure of a local FMU. Some also included the opening of a new AMU on a hospital site in a nearby town or city.

Across all the services, the articles were dominated by two main problems that were posited as leading to an inevitable or unavoidable decision to close the FMUs first, that women are not choosing to give birth in FMUs:

'Grantham's maternity unit has apparently been falling out of favour, with only 100 women delivering their babies their last year, compared to almost 4,000 in Lincoln and just over 2,000 in Boston'. ${ }^{17}$

and second, that these units are too expensive to justify remaining open and being subsidised by the hospital trust:

'The locality believes that the extra costs associated with the unit are not sustainable in the financial climate the NHS is now in'. (Journalist in Ref. ${ }^{18}$ )

These two problems, under-use and cost, are represented by the articles as the central drivers of the solution (closure). A deeper analysis of these arguments aims to interrogate the presuppositions that lie behind them. 


\subsubsection{Question 2: What presuppositions or assumptions underlie this representation of the 'problem'?}

The construction of the two problems represented by the articles was influenced by our prevailing cultural norms. There are three particular norms around birth that relate most directly to the 'problems' of under-use and cost that have become taken for granted 'common-senses':

1. That being close to medical back-up makes a service safe

Dominant discourses about midwifery units, and maternity services, privilege a medical model of care that is likely to include the following presuppositions:

- That birth is inherently risky ${ }^{19}$

- That the safest place to give birth is in an obstetric unit, where obstetricians are present

- That the further a birth place is from an obstetric unit, the less safe it is ${ }^{20-22}$

The newspaper coverage appeared to present a binary relationship between this medical model of care and a contrasting social model of care, represented by those in support of keeping the units open:

'The vast majority [of women in Grantham] opt to give birth at other hospitals where they can get:

- Direct access to obstetricians, anaesthetists and neonatologists,

- Access to other specialist services such as epidurals for pain relief,

- There is a specialist care baby unit if there are any problems.

None of which they can currently get at the Midwifery Led Birthing Unit at Grantham Hospital'. (Journalist in Ref. ${ }^{23}$ )

"The service provided there [Jubilee Birth Centre] is amazing. There is a lovely atmosphere and it is one of a kind. We are lucky to have it and this is a blow for our area." (Unidentified speaker in Ref. ${ }^{24}$ )

In the case above, campaigners supported their FMU because its birth environment represented the social model of care they desired. These opposing models of care were not necessarily linked to one type of birth place or another. In Grantham and in Kent, keeping birth local was a more important element of the social model promoted by campaigners, than ensuring that births took place in an FMU per se. In Kent, campaign messages emphasised the importance of women being able to birth locally to avoid long journeys in labour and to retain birth within the local community:

'The move would force Canterbury mothers-to-be into long journeys to hospital and mean Kent's only city would disappear from birth certificates.' (Journalist in Ref. ${ }^{25}$ )

However, instead of campaigning to keep their FMU as it was, local service users and campaigners in Grantham instead fought for it to be returned to an obstetric unit rather than closed. This would enable more women to birth in their hometown. These campaigners utilised a broad concept of 
safety, incorporating notions of wellbeing and community, rather than simply the presence or absence of medical back-up.

2. That women have the freedom to choose their place of birth

By asserting the 'problem' that women don't choose to birth in FMUs, Trust CEOs, commissioners and some journalists drew on the presupposition that women have a free and informed choice about where they plan their births. Those in favour of closures asserted that the FMUs were undesirable, so women were not choosing to birth there and instead travelling elsewhere for obstetric unit care. Whilst the raw birth figures may suggest this to be true, it did not take into consideration the complex influences on women's choices of place of birth. A range of studies have indicated that women are offered limited and often not evidence- based information by service providers (see for example Ref. ${ }^{26}$ ) and that the choice to plan birth out of hospital is highly constrained by social norms.

Service users and campaigners argued that the FMUs remained desirable, but that many women were not able to choose them due to eligibility guidelines or a lack of information:

"I think one of the fundamental issues is the lack of publicity the centre gets from GPs and midwives at booking-in appointments. Two friends of the family who are expecting didn't know the Jubilee Birth Centre existed until I told them!

Surely all healthcare professionals that are the first point of call in pregnancy should be offering both choices, not just what they think is best, or safest in the case of a first-time mum?" (Service User in Ref. ${ }^{28}$ ).

A limited number of the user voices included questioned assumptions around women's wishes and choices whilst professional and service commissioner voices spoke about lack of demand as a given fact:

'Lindsey Stevens, head of midwifery at the East Kent Hospitals University NHS Foundation Trust, said that for a "very small number" of women the choice would be taken away. "Safety has to be our primary concern," she said. "Dover and Deal midwives are very passionate about the service they give. I am sure they give home birth and Dover Birthing Centre as a choice."

[...] Cllr Hawkins said she was sure it depended on how the choice was put to people as to how they responded. "The way the choice is worded will have an effect on the result of their choice," she said.

Miss Stevens said some would not have been given the choice because of their medical situation.

"It's not appropriate for them," she said.' (Local politician in Ref. ${ }^{29}$ )

The dominant discourse was that the locus of control was in women's decision-making, and women were not choosing FMU care: 
"'The midwives do a great job but women are clearly choosing to go elsewhere for their care.' (CCG Accountable Officer in Ref. ${ }^{23}$ )

Some voices did question this prevailing discourse, arguing that women's choices are constrained in practice:

“'Half the pregnant ladies were not given the chance to use it. They were told, you have to go to Lincoln"' (Campaigner in Ref..$^{30}$ )

Women's choices of place of birth are guided and constrained by social and cultural norms and ideas about risk/safety and appropriate birth places, family traditions and information from friends and family. In addition, evidence strongly suggests that healthcare professionals may also 'steer' women's choices by offering little information about alternatives to obstetric unit birth ${ }^{45}$, resulting in what has been variously called 'protective steering' ${ }^{31}$ or 'informed compliance $^{32}$ :

Midwives were observed to "frame" information and "steer" women towards making the "right" decisions to "protect" themselves and their clients from the consequences of inadvertently disrupting the status quo. (...) Unequal power relations resulted in bias towards the "objective" knowledge of health professionals and marginalised women's subjective knowledge. Hence, power differentials served to reinforce informed compliance with the right choice rather than encourage informed choice. $32,4-5$

3. That health services should be sustaining

CEOs and commissioners used the articles to explain how much money they considered the FMU was costing their service, quoting the specific amount of money that they perceived was 'lost' each year. In some cases, the financial losses were attributed directly to women's decisions on place of birth:

"Only 274 out of 5,440 new mothers from Brent gave birth there in 2006, along with 18 from Harrow, leading to a deficit of $£ 300,000$ a year." (Journalist in Ref. ${ }^{33}$ )

In Brent, where the FMU had been opened on the site of a closed obstetric unit, the CEO presented his decision to close the unit as a moral one:

I have a responsibility to make the best use of taxpayers' money and the Brent Birthing Centre is losing $£ 300,000$ a year. As an accountable officer, that is not something I can sustain. (Chief Executive in Ref. ${ }^{34}$ )

These justifications for closure on the grounds of cost linked to women's choices, failed to take into account the influences on women's decision-making, as well as presupposing that FMUs should always be financially self-sustaining.

Articles deployed a combination of managerialist and consumerist discourses, whereby managers were depicted as sharing limited resources out for the greater good, whilst women exercised a 'free, consumer choice' not to birth in FMUs:

It's important we provide the best care possible for every pound spent, for everyone in Derbyshire (Medical director in Ref. ${ }^{35}$ ) 
Such a discourse, aligning notions of consumerism with those of public service, is compelling, as it argues that reconfiguration is driven by equity. It represented that where consumers are not choosing something, any that do make that choice render it inequitable. In contrast, service users and campaigners presented a parallel discourse, based on human rights, where they considered that Trusts had a duty to support women's rights to birth locally by providing these places of birth.

In these eight services, changes were questioned by service users using emotive language that drew on images of family, home and community:

"'Both of my children were born there as were their mother and I was therefore hoping to see a third generation eventually come into the world at Buckland"'. (Philip Moore, local father, in Ref. ${ }^{36}$ )

“'Giving birth is one of the biggest things you do as a woman. It's outrageous that they don't have the choice to have their babies in their local hospital"'. (Service User in Ref. ${ }^{37}$ )

The consumerist model constructs the health service as a 'market' that generates income through consumers' use, whereby the service sustains itself through its own generated income. This mitigates against the more comprehensive analysis provided by health economic evaluation, which takes into account the impact for other parts of the system (for example, the costs of higher intervention rates in OUs or public health benefits). A 'rights' model implies instead that a hospital Trust would have some responsibility to provide a clinically effective service regardless of whether or not it was financially self-sustaining. Thus different ways of representing a 'problem' are driven by different presuppositions.

\subsubsection{Question 3: How has this representation of the 'problem' come about?}

Historical policies that moved birth into the hospital had a long lasting impact on where women chose to have their babies. Despite a number of more recent initiatives that have advocated for women's choice of place of birth including midwifery units and home, ${ }^{4-6}$ and strong evidence to the contrary, a widespread belief persists that obstetric units are the safest place to have a baby and that the closer a woman is to an obstetric unit, the safer she will be. ${ }^{21,38}$

Our content analysis revealed that very little of the media reporting focused on safety per se, and made very little reference at all to clinical evidence; this was instead implicit in the arguments in support of the closure of FMUs in favour of AMUs:

"'We feel that a midwife-led unit close to the maternity department would provide the best of both worlds the possibility of a natural birth without medical intervention, but the security of knowing an obstetrician is close by in case of emergencies.'" (Trust Chief Executive in Ref. ${ }^{39}$ )

The risks are perceived as both clinical and financial. Changes to local healthcare systems may represent a withdrawal of public services from areas already disadvantaged or feeling the impact of austerity, such as rural or deprived urban areas, which have been disproportionately affected by Local Authority budget cuts. ${ }^{40}$ In the 10 years since the global economic collapse of 2007/08, austerity in the UK and in many other countries has become the 'new normal'. For the NHS, where increases in spending have not kept pace with even greater demand, the presence or absence of money is presented as an irrefutable economic fact, divorced from any political intent. The political 
(as opposed to purely financial) motives behind austerity have, however, been widely criticised (see for example Ref. ${ }^{41,42}$ ).

Neoliberalism has moved centre stage in British politics and with it, an emphasis on the power of the market to solve economic and social problems. Neoliberalist policies are founded on the presumption that market mechanisms generate profit and allow all individual citizens equal access to the benefits of the market, which includes choice. ${ }^{43}$ In the case of maternity care, this presumes that women are able to make free choices about their place of birth, are choosing to birth in obstetric units and so FMUs, undesirable and under-used, should inevitably be closed:

'Neoliberalism's reliance on the 'free self-actualizing individual' as the subject of its philosophy limits its capacity to analyze the social relations within which individuals are born, raised, and live out their lives'. $44: 1$

Previous analyses have suggested that forces of historical policies around place of birth guide women away from birthing in FMUs. ${ }^{45}$ The dominance of neoliberalist politics then allows the resultant limited use of FMUs to be constructed as the financially unsustainable under-use of FMUs, framed as a simple 'demand and supply' issue that should inevitably lead to their closure. The language of austerity supports those assertions by managers and CEOs that FMUs are simply unaffordable and the normalisation of this rhetoric makes it almost impossible to propose any alternative scenarios.

5.3.4. Question 4: What is left unproblematic in this problem representation? Where are the silences? Can the 'problem' be thought about differently?

Commissioners and CEOs presented these problems, through the newspaper articles, as originating from forces external to the NHS Trust; as regrettable, necessary, inevitable and out of their control:

'The Jubilee Birth Centre, which had to close 66 times before December due to staff sickness and is running at a loss of $£ 120,000$ a year, is expected to reopen on Monday.

(...)

“There isn't anything to hide. The figures are what the figures are.

"It's about how you provide the best model of maternity service for the area. We can't continue to run the whole service in this way and something has to change."' (Hospital Trust CEO in Ref. ${ }^{46}$ )

The two problems both reflect and help to construct a neoliberal social norm whereby it is ultimately desirable for patients to have as much choice as possible, but the lack of money in the public purse to provide options is seen as inevitable in the 'current climate'.

A second representation that remained unproblematic in the discourse examined is that there was very little, if any, distinction made between FMUs and AMUs, apart from size and location. The evidence shows that there are benefits to FMUs as compared with AMUs as well as OUs in terms of cost and clinical effectiveness. ${ }^{8,9}$ In many of our eight cases, the proposed changes involved the closure of the FMU and the opening of an AMU in another of the Trust's hospitals. This was at times framed as a 'relocation' of the FMU, rather than a closure and in the case of the Brent Birth Centre the new AMU was given the same name as the closed FMU: 
'Maria Palko, 30, of Belmont Road, Wealdstone, was one of the first women to deliver a baby at Brent Birth Centre since it moved from Central Middlesex due to financial problems'. (Journalist in Ref. ${ }^{33}$ )

Campaigners supporting the Jubilee birth centre in Hull were reported as satisfied with the Trust's proposal to 'relocate' the FMU to the main hospital to become an AMU:

'Jubilee Supporters' Group campaigner Sian Alexander, 32, of west Hull (...) said: "While I am sad to see the Jubilee close permanently, I'm glad the trust at least acknowledges the importance of midwifery-led care and I hope the spirit of the Jubilee will be able to live on, albeit in another place".

[Claire Tomlinson, 33,] said: "If it is going to be exactly the same as the Jubilee was and it has all the same ethics, I think it's brilliant"'. (Service User Campaigner in Ref. ${ }^{47}$ )

The lack of distinction between FMUs and AMUs thus renders invisible the particular benefits of FMU care, for example, reduction of clinical interventions and serious maternal morbidity, in addition to possible (unmeasured) social or community benefits.

\subsubsection{Question 5: What effects are produced by this representation of the 'problem'?}

Whilst it is the voices of the service users who appeared most frequently in these articles, we suggest that the commissioners and CEOs held the narrative power. Aside from very few examples, users in support of closure are referred to through a third party rather than quoted directly, for example through decision-maker reports of the findings of a consultation. Similarly, the voices of midwives - those who manage and provide the services on which this analysis focused - were only reported indirectly, through the voices of commissioners, general service or (rarely) nursing managers.

'Dr Evans [Clinical Director of CCG] said: "The strong message from midwives at the freestanding unit is they want to provide good care. Although they are very pleased with the care they provide, they are noticing their numbers are going down and quite supportive of this change."' (Commissioner in Ref. ${ }^{49}$ )

This did not simply put them at a disadvantage in terms of the discourse around closure but implied that there was no other possible position. Socially powerful voices frequently framed the closures as 'gains', for example the opening of the new AMU, or more money to invest in other services:

'I hope that most of the Journal's readers will be reassured to know that the changes that have been announced this week will bring about an expansion in the services on offer at Grantham Hospital and an improvement in the treatment and care given to local people'. (Nick Boles, MP in Ref. ${ }^{50}$ )

In contrast, the arguments against closures were more likely to be framed in terms of a 'loss': the loss of the unit, of local services and possible implications for the economic wellbeing of a local community, and other local services:

'Yesterday Chronicle readers took to our Facebook page to hit out at the new proposals. Claire Louise Keys wrote: "So North Tyneside General now has no working age adult inpatient psychiatry wards, will soon have no A\&E and likely no maternity at all after already 
being degraded. What is to become of NTGH? A cottage hospital where people go to die in old age? The demise of hospital services for residents of North Tyneside is disgraceful."'

(Service User in Ref. ${ }^{51}$ )

The closely mirrored wording of many reports on the same service suggests reporters drew heavily on press releases. These press releases and the rationales they offered for decisions constructed a clear frame for these articles and the voices (or reported opinions) of women, partners, or campaigners were offered as a foil against this dominant frame:

'The organisation's [NHS Derbyshire] assistant director of commissioning, Sally Savage, put forward the case for closure. (...)

She said: "We want to provide a whole range of maternity services in rural communities and, because of the relatively high cost and relatively low usage of the birth centres, that money could be better used elsewhere." Women who would have used the centres will have the option of going to hospital or having a home birth.

(...) Campaigner Pam Wildgoose attended the meeting in her role as secretary of Matlock Hospitals League of Friends, which has led the battle against the closure of the Darley centre. She said: "I'm disappointed with the decision. They haven't addressed the issue of the lack of publicity about the centre. A lot of people don't realise it exists.",'

\subsubsection{Question 6: How and where has this representation of the 'problem' been produced,} disseminated, and defended? How could it be questioned, disrupted, and replaced?

In these articles, the voices of the service users, sometimes through the intervention of local politicians attempt to disrupt the framing narrative. They offer objection to the proposals, but their task of refuting the dominant narrative is harder than it would have been than to frame the narrative in the first place. Service users are left with the job of working against arguments that are supported by a number of strong cultural assumptions including those of the superior safety of the medical model of care, that care in FMUs is not cost-effective because they are small and that women have free choices and by those who have the ultimate decision-making power.

\section{Conclusions and implications}

By analysing both the content and the discourse of media reporting, using a systematic approach, this set of media articles shed light on the public discourse and 'atmosphere' in which FMUs function and close. The arguments that are presented in favour and against these closures expose the cultural norms that influence and shape them. The arguments made in favour of closures are largely and unsurprisingly consistent with dominant conceptions of place of birth that exist in wider society. They privilege a medical model of birth and the perceived safety of birth close to an obstetric unit. They present midwifery units as unaffordable luxuries that women choose not to use. These arguments are given further power and weight by dominance of the dual discourses of austerity and neoliberalism in contemporary UK society. These discourses frame the ways in which the arguments are presented and also shape how they are received by the news media. Their resonance with dominant public beliefs about place of birth makes it easy for the public to receive the frames that are being presented, as they don't challenge what they might already think. The closure is also presented in terms of the gains - the gain of a new unit or of improved safety.

In contrast, the arguments presented by service users and campaigners attempt to refute some of these. They privilege a local, social model of care through which women can birth close to home, their families and communities. This is a challenging task. They act against the dominant frame of 
the articles, as well as the social norms that guide how the messages are received. The arguments against closures are also presented in terms of losses - loss of local services, loss of birth in the community, the risk of births during travel to the new hospital and so on. The arguments (on either side) are rarely supported by evidence on the cost or clinical outcomes of FMUs themselves, possibly as commentators lack access to such knowledge, but also because they are framed in terms of a wider and meaningful discourse about loss of the local and the potential negative social, cultural and economic impact on the community, issues which are not typically measured or even assessed in healthcare research.

The power of the WPR analysis is that it moves beyond the most obvious interpretations. Whilst a standard content analysis might suggest that the high incidence of quotes from service users means they have the privileged voice, the WPR analysis challenges this presumption. It shows that despite the 'air time' given to service users, the dominant discourse, and by association authoritative knowledge, lies with the healthcare managers and commissioners, and with the voices of midwives themselves being notably absent.

The articles themselves have the potential to provide local women with information about their services and choices of place of birth, which may itself have an impact on their future decisions. The articles lacked information on the different models of care and what they meant for women and their babies and it is likely that they reflect the quality of information on place of birth that women are receiving from many public sources such as print media, television, internet fora, as well as from healthcare professionals. A thorough consideration of the drivers that lie behind the arguments of cost and under-use has exposed the influences of the wider political landscape outside of maternity and indeed healthcare. The language of austerity and neoliberalism encircle the whole. Lack of money and the moral necessity of the market and free choice have become core to the way in which we understand our communities and public services. Framing the benefits of closures in this way makes them extremely difficult to refute. Yet an analysis of this process can begin to disrupt the idea that the decisions for closure are straightforwardly logical, inevitable, affordable, as the decisionmakers present them to be.

An analysis of well performing services as part of the Birthplace in England programme ${ }^{26}$ identified key features helping to sustain FMUs including positive leadership, integration of the unit into the wider service and integrated staffing models including both core FMU staff and community or caseload midwifery teams. The study also identified inequity of information and access with many women not receiving evidence-based information about birth- place options and a number of professionals not confident in providing it.

An alternative strategy could be that instead of simply putting the under-use of an FMU down to 'women's choice', Trusts might instead choose to increase its use by seeking to influence the cultural norms of place of birth (including amongst midwives) and improve the quality of information women are given. Initiatives such as promoting the integration of midwifery units into the maternity service and the active promotion of local midwifery units may make a difference to their uptake, despite the limited evidence to date. ${ }^{53}$

Local media could play a role in this. Our reading of local news media uncovered notable poor quality of reporting, including a lack of evidence-based information, and heavy reliance on press releases, which deserves further investigation. It is likely that this may be influenced by limited resources - a lack of specialist science or medical reporters, a broader lack of scientific or research literacy and an impact of the changes of the media landscape in the 21st Century that has moved resources away from print media. 


\section{Strengths and limitations of the research}

This study was limited to an analysis of media articles on units that closed within a specific time period. We did not consider media reporting on midwifery unit closures more generally. Despite taking a systematic approach to searches with data extraction cross- checked between researchers, it is possible that we missed some reports. We did not include analysis of any units that remained open after review or public consultation and this too would add another layer of understanding about media impact on discourse and decision-making. In addition, we did not access historical information on the history and context of these units, some of which had been opened in place of closed obstetric units as part of a wider centralisation policy. A more extended analysis might have thrown greater light on some of the issues discussed. The dominance of social media and its influence cannot be ignored and future analysis of the circulation of experiences and stories of service reorganisations and closures on social media would make an invaluable contribution to how we understand the micro-landscapes of health service reforms.

\section{Ethical statement}

Ethical approval is not required as this study draws only on written material - newspaper articles and television news transcripts - that are already freely available in the public domain.

\section{Acknowledgements}

This study is funded by the National Institute for Health Research, Health Service and Delivery Research, study reference: 14/04/28. Thank you to Ewan Rayment for technical support with the development of the Excel macro.

\section{References}

1. Walsh D, Spiby H, Grigg CP, Dodwell M, McCourt C, Culley L, Bishop S, Wilkinson L, Coleby D, Pacanowski L, Thornton J, Byers S. Mapping midwifery and obstetric units in England. Midwifery 2018;56:9-16.

2. Bacchi C. Analysing policy: what's the problem represented to be? Oxford: Pearson; 2009.

3. Macfarlane A, Mugford M. Birth counts: statistics of pregnancy and childbirth. London: The Stationery Office; 2000.

4. Department of Health. Changing childbirth: part i: report of the expert maternity group (Cumberlege Report). London: HMSO; 1993.

5. Department of Health. Maternity matters: choice access and continuity of care in a safe service. London: HMSO; 2007.

6. NHS England. Maternity review: better births - improving outcomes for maternity services in England. A five year forward view for maternity care. England, London: NHS; 2016.

7. Birthplace in England Collaborative Group. Perinatal and maternal outcomes by planned place of birth for healthy women with low risk pregnancies: the Birthplace in England national prospective cohort study. BMJ 2011;343:d7400. 
8. Hollowell J, Li Y, Bunch K, Brocklehurst P. A comparison of intrapartum interventions and adverse outcomes by parity in planned freestanding midwifery unit and births: secondary analysis of 'low risk' births in the birthplace in England. BMC Pregnancy Childbirth 2017;17(1):95.

9. Schroeder E, Petrou S, Patel N, Hollowell J, Puddicombe D, Redshaw M, Brocklehurst on behalf of the Birthplace in England Collaborative Group P. Cost-effectiveness of alternative planned places of birth in woman at low risk of complications: evidence from the Birthplace in England national prospective cohort study. BMJ 2012;344:e2292.

10. Dodwell M. Trends in freestanding midwife-led units in England and Wales. London: RCM; 2013.

11. McCombs M. Setting the agenda: mass media and public opinion. Cambridge: Polity Press; 2014.

12. Ball SJ. Foucault, power, and education. New York: Routledge; 2012.

13. Cacciatore WA, Scheufele DA, lyengar $S$. The end of framing as we know it and the future of media effects. Mass Commun Soc 2016;19:7-23.

14. Luce $A$, Cash $M$, Hundley V, Cheyne $H$, van Teijlingen $E$, Angell $C$. Is it realistic? the portrayal of pregnancy and childbirth in the media. BMC Pregnancy and Childbirth 2016;16(40).

15. MacLean E. What to expect when you're expecting? Representations of birth in British newspapers. Br J Midwifery 2014;22(8):580-8.

16. Dahlen H. Normal birth in a post truth world. Women Birth 2017;30(5):351-3. 17. East Midlands Today. 6:45 PM GMT Wednesday November 21. 2012.

18. Butler R. Cost of birth centre 'not sustainable' in present climate, says GP group. Derby Evening Telegraph; 2011 December 3.

19. Walker KF, Cohen AL, Walker SH, Allen KM, Baines DL, Thornton JG. The dangers of the day of birth. Br J Obstet Gynaecol 2014;121:714-8.

20. Royal College of Obstetricians and Gynaecologists. RCOG statement on the results of the NPEU Birthplace study. [Homepage of Royal College of Obstetricians and Gynaecologists]. 2011 . Available from: www.rcog.org.uk/en/news/rcog-statement-on-the-results-of-the-npeu-birthplace-study/.

21. McCourt C, Rayment J, Rance S, Sandall J. An ethnographic organisational study of alongside midwifery units: a follow-on study from the Birthplace in England Programme. HS\&DR:

Southampton; 2014

22. Pitchforth $\mathrm{E}$, et al. Choice and place of delivery: a qualitative study of women in remote and rural Scotland. Qual Saf Health Care 2009;18(1):42-8.

23. Graham N. Breaking news: Grantham Hospital to lose maternity unit in health shake-up. Grantham J 2012(November 21).

24. Wood K. Jubilee centre to shut after watchdog blow: NHS inspectors voice fears over birth unit staffing. Hull Daily Mail; 2011 July 27.

25. Williams A. Health bosses receive our 450 name petition. Kentish Gazette; 2011 October 20. 
26. McCourt C, Rance S, Rayment J, Sandall J. Birthplace qualitative organisational case studies: How maternity care systems may affect the provision of care in different birth settings. Birthplace in England research programme. Final report part 6. NIHR Service Delivery and Organisation programme; 2011.

27. Coxon KA, Sandall J, Fulop NJ. To what extent are women free to choose where to give birth? How discourses of risk, blame and responsibility influence birth place decisions. Health Risk Soc 2014;16(1):51-67. doi:http://dx.doi.org/ 10.1080/13698575.2013.859231.

28. Hull Daily Mail. I have Jubilee Centre staff to thank for my easy labour. Hull Daily Mail; 2011 March 10.

29. East Kent Mercury. Birth centre plan will reduce choice. East Kent Mercury; 2011 October 6.

30. BBC1YorkshireandLincolnshire,RegionalNewsandWeather-5:45PMGMT, 2013, June 26.

31. LevyV.Protectivesteering:agroundedtheorystudyoftheprocessesbywhich midwives facilitate informed choices during pregnancy. J Adv Nurs 1999;29 (1):104-12.

32. Stapleton H, Kirkham M, Thomas G. Qualitative study of evidence based leaflets in maternity care. BMJ 2002;324:

33. Royston J. First mother - I was happy with it. Kentish Gazette; 2008 July.

34. Kirk T. Birthing centre closure supported. Harrow Times; 2007 September 28.

35. Mallett, C. 'Overwhelming' support to save birth centre'. Derby Evening Telegraph; 2011 October 7.

36. East Kent Mercury. Chance to have say on future of birthing centre. East Kent Mercury; 2011 October 13.

37. Walker J. There'll be a boom in backseat babies. 2011 June 23.

38. Newburn M. An emerging model for maternity care: an ethnographic pilot study of an inner-city birth centre. London School of Hygiene and Tropical Medicine; 2009.

39. Editor. Maternity decision based on safety - comment on this story. Scarborough Evening News; 2008 May 1.

40. Hastings A, Bailey N, Bramley G, Gannon M, Watkins D. The cost of the cuts: the impact on local government and poorer communities. York: Joseph Rowntree Foundation; 2015.

41. Blyth M. Austerity: the history of a dangerous idea. Oxford: Oxford University Press; 2014.

42. Karger H. The bitter pill: austerity, debt and the attack on Europe's welfare states. J Sociol Soc Welf 2014;41(2):33-54.

43. McGregor S. Neoliberalism and health care. Int J Consum Stud 2001;25(2):82-9. 
44. Braedley S, Luxton M. Competing Philosophies: neoliberalism and challenges of everyday life. In: Braedly S, Luxton M, editors. Neoliberalism and everyday life. Montreal s University Press; 2010. p. 3-21.

45. Coxon K, Chisholm A, Malouf R, Rowe R, Hollowell J. What influences birth place preferences, choices and decision-making amongst healthy women with straightforward pregnancies in the UK? A qualitative evidence synthesis using a 'best fit' framework approach. BMC Pregnancy Childbirth 2017;17:103.

46. Hull Daily Mail. Health chief has 'nothing to hide' over birth centre. Hull Daily Mail; 2011 January 22.

47. Wood K Birthing centre will shut doors for good. Hull Daily Mail; 2012 February 1.

48. Walsh D. 'Nesting' and 'Matrescence' as distinctive features of a free-standing birth centre in the UK. Midwifery 2006;22(3):228-39.

49. News Guardian. Maternity unit will close as new hospital opens. News Guardian; 2014 March 26.

50. Boles N. Nick Boles: I support decision to close Midwifery Unit. Grantham J 2013(June 26).

51. Davies K. Mums lead calls to save at-risk maternity unit. Evening Chronicle; 2013 December 11.

52. Gulzar K. Campaigners lose battle to prevent birth centre closures. Derby Evening Telegraph; 2011 December 8.

53. Henshall C, Taylor B, Kenyon S. A systematic review to examine the evidence regarding discussions by midwives, with women, around their options for where to give birth. BMC Pregnancy Childbirth 2016;16(53). 